\title{
Index rerum
}

Aging, evolutionary considerations 153

Aging concepts, current status 155

Aging and disease 151

Arginine phosphokinase 203

Athero-arteriosclerosis 131-175

Athero-arteriosclerosis, definition and distribution 132

Athero-arteriosclerosis, and endocrine aberrations 167

Athero-arteriosclerosis, historical perspective 140

Athero-arteriosclerosis, and mis-specification-autoimmune (aging) theory 159

Athero-arteriosclerosis, implications of vital statistics 159

Biphasic age-specific curve 150 Blaibergcase 161 Bone marrow 1 Brain slices 224

Carbohydrate metabolism 224 Cell-mediated immunity 177 Colony-forming units 1 Coronary

thrombosis-myocardial infarction relationship 136 Crosslinking 73 Cytochemistry 95

Cytochrome oxidase 95

Development 102 Dietary restriction 184 Disc electrophoresis 124 DNA 73, 231

Drosophila melanogaster 73, 203, 231 Drosophila melanogaster, vestigial mutant 203

Electroencephalogram 21 Electron microscopy 81 Emotionality 46

Endocrine system 166 Endogenous colonies 1 Energy metabolism 31 Enzyme pattern 31 Error

catastrophe 57, 64 Exogenous colonies 1 Exploratory behaviour 46

Fibroblasts 64 Flight muscle 203,216 Formaldehyde 124 Fungi 64

Glycogen 216 Growth rate 102

Hamster 224 Homogenate 95 House fly 216

Immediate recall 10

Immune function 184

Intrinsic vascular immune responses 163

Learning 10

Life span 184

Liver 81,95

Locomotion 46

Longevity 102

Long-term retention 10

Lymphocyte transformation 177

Malate dehydrogenase 95

Methionine 124

Mice 1, 21, 46, 81, 95, 184

Mis-specification-autoimmune aging theory 159 Mis-specification-autoimmunity of the neuroendocrine system 165 Missynthesis 57 Mitochondria 81, 95, 216, 231 Index rerum 
Muscle 31 Myofibrils 216

Nucleic acids 211 Nutrition 184

Open-field behaviour 46 Organ-nonspecific antibodies 117 Organ-specific antibodies 117 Orgel hypothesis 57, 64, 240

Parental age 102 Phosphatases 211 Productivity 102 Prostate 211 Proteins 64

Rapid-eye movement 21 Rat 31,211 Rat tail 124 Respiration 224 Risk factors 138

Slow-wave sleep 21 Spleen 1

Strain difference 46 Survival 184

Tendon collagen 124 Testosterone 211 Tribolium 102

Uptake in vitro 211

Viability 102 